\title{
Association of non-alcoholic fatty liver disease with cardiovascular disease and subclinical atherosclerosis
}

Rahul Sao, Wilbert S. Aronow

Cardiology Division, Department of Medicine, Westchester Medical Center/New York Medical College, Valhalla, NY, USA

Submitted: 3 March 2016

Accepted: 19 May 2016

Arch Med Sci 2018; 14, 6: 1233-1244

DOI: https://doi.org/10.5114/aoms.2017.68821

Copyright $\odot 2017$ Termedia \& Banach

\section{Abstract}

Non-alcoholic fatty liver disease (NAFLD) refers to fatty infiltration of liver in the absence of significant alcohol intake, use of steatogenic medication, or hereditary disorders. It is a common cause of chronic liver disease with a worldwide estimated prevalence ranging from $6.3 \%$ to $33 \%$. The NAFLD is considered a hepatic manifestation of the metabolic syndrome. Insulin resistance and increased oxidative stress are central to pathogenesis of NAFLD, and risk factors include metabolic syndrome, diabetes mellitus, obesity, lack of physical activity, smoking, and high fat diet. NAFLD is associated with higher mortality as compared to the general population with cardiovascular disease being the most common cause of death. The NAFLD is associated with a higher prevalence of subclinical atherosclerosis as evidenced by odds of higher coronary artery calcification, higher average and maximum carotid intima-media thickness. It is also associated with stiff arteries as evidenced by higher cardio-ankle vascular index and higher brachial-ankle pulse wave velocity. Increasing evidence has linked NAFLD with atherosclerotic cardiovascular diseases. The NAFLD is associated with a higher prevalence of coronary artery disease (CAD), more severe CAD, poor coronary collateral development, and higher incidence of coronary events. The NAFLD is also associated with ischemic stroke. Studies have shown that the association between NAFLD and atherosclerotic cardiovascular diseases is independent of shared risk factors.

Key words: non-alcoholic fatty liver disease, coronary artery disease, atherosclerotic cardiovascular disease.

\section{Introduction}

Non-alcoholic fatty liver disease (NAFLD) is a common cause of chronic liver disease with increasing worldwide prevalence. Non-alcoholic fatty liver disease is defined by imaging or histological evidence of fatty infiltration of liver in the absence of known causes of fat accumulation in the liver including significant alcohol consumption [1]. Non-alcoholic fatty liver disease is a spectrum of disease ranging from simple steatosis (NAFL or non-alcoholic fatty liver) without evidence of hepatocellular injury to non-alcoholic steatohepatitis (NASH) marked by inflammation with hepatocyte injury with or without fibrosis [1, 2]. Non-alcoholic fatty liver disease may or may not be associated with aminotransferase elevation [1].

Due to widespread availability and low cost, ultrasound is the preferred initial radiological study to assess for fatty infiltration of liver $[3,4]$.

\author{
Corresponding author: \\ Prof. Wilbert S. Aronow MD, \\ FACC, FAHA \\ Cardiology Division \\ New York Medical College \\ Macy Pavilion, Room 141 \\ Valhalla, NY 10595, USA \\ Phone: (914) 493-5311 \\ Fax: (914) 235-6274 \\ E-mail: wsaronow@aol.com
}


Non-alcoholic steatohepatitis represents more advanced stage of the disease and has an inflammatory component in addition to fat accumulation [1]. Non-alcoholic steatohepatitis may further progress to cirrhosis and or to hepatocellular carcinoma [5]. Various non-invasive methods such as the NAFLD fibrosis score [6], Enhanced Liver Fibrosis (ELF) panel, presence of circulating biomarkers (cytokeratin-18) can identify advanced fibrosis [7]. However, liver biopsy is the 'gold standard' for assessing the histology in NAFLD and accurately identifying NASH. Metabolic syndrome predicts the presence of steatohepatitis in NAFLD patients and its presence should guide the decision to obtain liver biopsy [1].

Non-alcoholic fatty liver disease is sometimes referred to as the hepatic manifestation of metabolic syndrome $[8,9]$. It is associated with higher overall mortality as compared to the general population [10, 11]. Cardiovascular diseases are the most common cause of death among patients with NAFLD [9-11] while liver disease is the third leading cause $[11,12]$. The aim of this paper is to review the available literature linking NAFLD and cardiovascular disease.

Because of shared risk factors with the metabolic syndrome, NAFLD was considered as a mere marker of cardiovascular disease. However, studies are available that show an association between cardiovascular disease and NAFLD independent of shared risk factors [13-16].

\section{Epidemiology}

The reported incidence of NAFLD varies widely. A retrospective analysis reported an annual incidence of 29 per 100,000 patient years [17]. Another prospective study in a Japanese population reported 308 new cases among $3147 \mathrm{pa}$ tients during a 414 days follow-up period [18]. The wide variation in reporting indicates the need for a better study to calculate the actual incidence rates.

The prevalence of NAFLD has been increasing in recent times. The reported prevalence varies based on the population studied and modality used to establish the diagnosis. The worldwide prevalence in the general population ranges from $6.3 \%$ to $33 \%$ with a median of $20 \%$ [1]. The prevalence is much higher in a high-risk patient population. Machado et al combined 12 observational studies including 1620 patients with morbid obesity and reported a 91\% prevalence (range: $85-98 \%$ ) of NAFLD in this population group [19]. Two separate studies quoted a prevalence of ultrasonographic NAFLD in diabetic patients at $69.4 \%$ [20] and $67.8 \%$ [21]. Another study in patients referred to a urban hospital-based lipid clinic showed a NAFLD prevalence of $50 \%$ [22].

\section{Etiopathogenesis and risk factors}

Day and James explained the pathogenesis of NAFLD in 1998 by 'two-hit hypothesis' [23]. The first physiological event is insulin resistance. Insulin resistance manifests not only at the level of muscles but also at the level of liver and adipose tissue [24]. The combined effect of hyperinsulinemia and insulin resistance leads to an increased absolute hepatic free fatty acid uptake and increased esterification to triglycerides among other mechanisms leading to hepatic steatosis [25]. It should be stressed that insulin resistance is a cause of NAFLD rather than being its effect as shown by studies in genetically predisposed NAFLD subjects who have insulin sensitivity comparable to matched subjects without NAFLD [26-28].

The second physiological event is increased oxidative stress $[25,29]$. Oxidative stress plays a dual role by contributing to steatosis due to higher peroxidation of lipids and by promoting progression of steatosis to steatohepatitis. A study has shown a higher rate of lipid oxidation and impaired suppression of hepatic lipid oxidation by insulin in patients with NAFLD [24].

With better understanding of the pathogenesis of NAFLD, a 'multiple parallel hits' hypothesis has gained more acceptance [30, 31]. Insulin resistance and its metabolic disturbance constitute the first hit resulting to fat infiltration of liver. This is followed by multiple parallel hits, leading to hepatocyte injury and progression from simple steatosis to NASH and fibrosis [30].

Cytokines play an important role in insulin resistance and NAFLD [32]. Higher levels of pro-inflammatory cytokine tumor necrosis factor- $\alpha$ (TNF- $\alpha$ ) are associated with increased insulin resistance [33]. Mice lacking TNF- $\alpha$ were shown to have improved insulin sensitivity [34]. Haukeland et al. demonstrated higher levels pro-inflammatory cytokines interleukin-6 (IL-6), chemokine ligand 2/ monocyte chemoattractant protein-1 (CCL-2/ MCP-1), TNF- $\alpha$ and decreased level of adiponectin among patients with NAFLD compared to controls [35]. IL-6 expression is markedly increased in patients with NASH as compared to patients with NAFLD or normal liver histology [36]. Anti-inflammatory adipocytokine adiponectin levels are lower in patients with hepatic steatosis and NASH [37].

Obesity has a strong correlation with insulin resistance and NAFLD [38-40]. The prevalence of NAFLD among morbidly obese patients based on a meta-analysis was 91\% (range: 85-98\%) [19]. There is evidence that weight loss among obese patient with type II diabetes mellitus can normalize insulin sensitivity [41]. Another study showed that weight loss can prevent progression of glucose intolerance to type II diabetes mellitus [42]. 
Choudhary et al. prospectively studied 16 living related liver donors with significant steatosis based on liver histology. Donors were recommended $1200 \mathrm{Kcal} /$ day diet and $60 \mathrm{~min} /$ day moderate cardiovascular training. Repeat liver biopsy done at $28 \pm 10$ days showed a decrease in steatosis in all but one subject including normalization of the liver biopsy in 7 donors [43]. A review of the literature of bariatric surgery showed significant improvement and resolution of steatosis with bariatric surgery [44]. However, in patients with established hepatic fibrosis, there are conflicting data about the outcome of metabolic procedures. Some studies have shown that metabolic procedures are associated with worsening of fibrosis in patients with advanced fibrosis $[45,46]$. However, a few including prospective studies have also shown improvement in fibrosis after a bariatric procedure $[45,47]$.

The use of exercise is a well-established prevention and therapeutic recommendation for NAFLD [48]. Increased physical activity not only plays a protective role against many risk factors of NAFLD such as obesity, metabolic syndrome, hyperlipidemia, and insulin resistance, but also has independent beneficial effects. In a cross-sectional study, physical activity was inversely proportional to the prevalence of NAFLD in a dose dependent manner that was independent of visceral obesity and insulin resistance [49]. Another cross-sectional analysis of non-diabetic Korean individuals showed that regular exercise was associated with a reduced risk of having NAFLD and decreased liver enzymes in patients with NAFLD [50].

Smoking has been implicated as a risk factor for NAFLD in several case control studies. Three separate studies in a Chinese population has established cigarette smoking as risk factors and its interaction with genetic polymorphisms of MCP-1 receptor CCR2 gene 190A/G (GG), NADPH oxidase subunit p22phox gene C242T [51], LEPR gene Gln223Arg, MnSOD9Ala/Val [52], AdipoR2 gene +33371Gln/Arg, and CYP2E1-Rsa I [53], increasing the risk even further. The odds of cases being smokers as compared to controls in these three studies were 3.3032 [51], 3.6754 [52], and 2.5919 [53].

High fat diet is a precursor for insulin resistance [54] and a risk factor for NAFLD. Wiedemann et al. showed induction of hepatic insulin resistance by 4 days of a high fat diet ( $52 \%$ fat calories) in mice [55]. Pan et al. have shown that more than $70 \%$ of mice that were a fed high fat diet $(42 \%$ fat calories) developed NAFLD at 12 weeks [56].

\section{Non-alcoholic fatty liver disease and subclinical atherosclerosis}

Insulin resistance is the cornerstone of NAFLD pathogenesis and is closely associated with the metabolic syndrome. Non-alcoholic fatty liver disease, insulin resistance, and the metabolic syndrome share multiple risk factors. Some authors have referred to NAFLD as a hepatic manifestation of the metabolic syndrome. Non-alcoholic fatty liver disease accelerates development and progression of atherosclerosis. However, disagreement exists whether NAFLD is a risk factor of atherosclerosis beyond its association with the metabolic syndrome [57]. Studies are available that show an association between NAFLD and subclinical atherosclerosis. Most of them prove this association is independent of the metabolic syndrome and traditional cardiovascular risk factors (Table I).

Coronary artery calcification (CAC) is a surrogate marker for atherosclerotic burden and an independent marker of coronary heart disease (CHD) risk [58]. Sung et al. analyzed data from a South Korean occupational cohort of 10,153 individuals who received an ultrasound of the abdomen for assessment of fatty liver and a cardiac computerized tomography (CT) computed CAC score. Fatty liver was associated with a CAC score $>0$, independent of all metabolic syndrome features $(\mathrm{OR}=1.21 ; 95 \% \mathrm{Cl}: 1.01-1.45)$ [59]. An evaluation of 505 non diabetic, asymptomatic men free of known CHD showed a positive correlation between hepatic steatosis diagnosed by ultrasound and CAC quantified by an electron beam tomography scan. The prevalence of CAC was higher among patients with hepatic steatosis ( $52 \%$ vs. $37 \%, p=0.001)$. This association was statistically significant after adjustment for age, $\mathrm{CHD}$ risk factors, and liver enzymes [60].

Another study included 2424 participants from the Coronary Artery Risk Development in Young Adult Study [61]. This study used CT to quantify liver fat, CAC, and abdominal aortic calcification (AAC). Patients with NAFLD had an increased prevalence of CAC $(37.9 \%$ vs. $26.0 \% ; p<0.001)$ and AAC $(65.1 \%$ vs. $49.9 \% ; p<0.001)$. The association of NAFLD with CAC and AAC persisted after adjustment for demographics and health behaviors. However, this association did not reach statistical significance after adjustment for visceral adipose tissue [61]. A more recent study involved a cross-sectional analysis of 3796 participants in the Multi-Ethnic Study of Atherosclerosis (MESA) study. This study showed that NAFLD is associated with increased inflammation and CAC independent of traditional risk factors, obesity, and the metabolic syndrome [62]. There was a graded association between NAFLD, obesity, and the metabolic syndrome with inflammation and CAC.

Measurement of carotid intima-media thickness (CIMT) using ultrasound is a marker of subclinical atherosclerosis. Carotid intima-media thickness is a strong predictor of future vascular 
Table I. Studies showing association of non-alcoholic fatty liver disease and subclinical atherosclerosis

\begin{tabular}{|c|c|c|c|c|c|c|c|}
\hline Author & Year & Country & Study design & Subjects & $\begin{array}{l}\text { Vascular } \\
\text { pheno- } \\
\text { type }\end{array}$ & $\begin{array}{c}\text { OR }(95 \% \mathrm{Cl}) \text { or } \\
p \text {-value }\end{array}$ & $\begin{array}{c}\text { Results } \\
\text { significant } \\
\text { after regression } \\
\text { analysis } \\
\end{array}$ \\
\hline Santos [60] & 2007 & Brazil & $\begin{array}{c}\text { Cross-sectional } \\
\text { analysis }\end{array}$ & 505 & CAC & $\begin{array}{c}1.49 \\
(1.00-2.21)\end{array}$ & Yes \\
\hline Sung [59] & 2012 & $\begin{array}{l}\text { South } \\
\text { Korea }\end{array}$ & $\begin{array}{c}\text { Cross-sectonal } \\
\text { analysis }\end{array}$ & 10,153 & CAC & $\begin{array}{c}1.21 \\
(1.01-1.45)\end{array}$ & Yes \\
\hline $\begin{array}{l}\text { Vanwagner } \\
\text { [61] }\end{array}$ & 2014 & USA & $\begin{array}{c}\text { Cross-sectional } \\
\text { analysis }\end{array}$ & 2424 & $\begin{array}{l}\text { CAC } \\
\text { AAC }\end{array}$ & $\begin{array}{l}\text { CAC: } 1.72 \\
(1.29-2.28) \\
\text { AAC: } 1.85 \\
(1.40-2.46)\end{array}$ & $\begin{array}{l}\text { CAC: No } \\
\text { AAC: No }\end{array}$ \\
\hline Rifai [62] & 2015 & USA & $\begin{array}{c}\text { Cross-sectional } \\
\text { analysis }\end{array}$ & 3976 & $\begin{array}{c}\text { CAC } \\
\text { Inflam- } \\
\text { mation } \\
\text { (hsCRP) }\end{array}$ & $\begin{array}{l}\text { CAC: } 1.63 \\
(1.34-1.98) \\
\text { hsCRP: } 2.22 \\
(1.85-2.67) \\
\end{array}$ & $\begin{array}{l}\text { CAC: Yes } \\
\text { hsCRP: Yes }\end{array}$ \\
\hline Thakur [64] & 2012 & India & $\begin{array}{c}\text { Cross-sectional } \\
\text { analysis }\end{array}$ & 80 & CIMT & $\begin{array}{c}\text { Average CIMT: } \\
4.8(1.8-12.8) \\
\text { Maximum CIMT: } \\
5.4(2.0-14.4) \\
\text { FMD: } 11.7(1.4-96.5)\end{array}$ & Yes \\
\hline Targher [65] & 2005 & Italy & $\begin{array}{l}\text { Case-control } \\
\text { study }\end{array}$ & 90 & CIMT & $\begin{array}{c}\text { CIMT values: } \\
1.10 \pm 0.20 \text { vs. } \\
0.84 \pm 0.13 \\
(p<0.001)\end{array}$ & Yes \\
\hline Huang [66] & 2011 & China & $\begin{array}{c}\text { Cross-sectional } \\
\text { analysis }\end{array}$ & 8632 & $\begin{array}{c}\text { CIMT } \\
\text { baPWV }\end{array}$ & $\begin{array}{c}\text { CIMT: } 1.48 \\
(1.17-1.86) \\
\text { baPWV: } 1.50 \\
(1.29-1.75)\end{array}$ & $\begin{array}{c}\text { CIMT: Yes } \\
\text { baPWV: Yes }\end{array}$ \\
\hline Kim [70] & 2009 & $\begin{array}{l}\text { South } \\
\text { Korea }\end{array}$ & $\begin{array}{c}\text { Cross-sectional } \\
\text { analysis }\end{array}$ & 1021 & CIMT & $\begin{array}{c}2.32 \\
(1.65-3.27)\end{array}$ & Yes \\
\hline Wang [69] & 2009 & Taiwan & $\begin{array}{l}\text { Prospective } \\
\text { cohort study }\end{array}$ & 169 & CIMT & $\begin{array}{l}\text { ALT (every } 10 \mathrm{IU} / \mathrm{I} \\
\text { increment) } \\
1.44(1.09-1.89)\end{array}$ & Yes \\
\hline $\begin{array}{l}\text { Agarwal } \\
{[68]}\end{array}$ & 2011 & India & $\begin{array}{l}\text { Prospective } \\
\text { cohort study }\end{array}$ & 124 & CIMT & $\begin{array}{c}\text { Mean CIMT } 0.71 \\
\pm 0.19 \mathrm{~mm} \text { vs. } \\
0.67 \pm 0.22 \\
p=0.213\end{array}$ & Yes \\
\hline Kang [67] & 2012 & $\begin{array}{l}\text { South } \\
\text { Korea }\end{array}$ & $\begin{array}{c}\text { Cross-sectional } \\
\text { analysis }\end{array}$ & 663 & CIMT & $\begin{array}{c}1.98 \\
(1.44-2.73) \\
\end{array}$ & Yes \\
\hline $\begin{array}{l}\text { Ampuero } \\
\text { [71] }\end{array}$ & $\begin{array}{l}2009- \\
2012\end{array}$ & & Meta-analysis & 1947 & CIMT & $\begin{array}{c}2.04 \\
(1.65-2.51)\end{array}$ & Yes \\
\hline Yu [79] & 2014 & China & $\begin{array}{c}\text { Cross-sectional } \\
\text { analysis }\end{array}$ & 1296 & baPWV & $\begin{array}{c}1321 \pm 158 \mathrm{~cm} / \mathrm{s} \text { vs. } \\
1244 \pm 154 \mathrm{~cm} / \mathrm{s} \\
p<0.001\end{array}$ & Yes \\
\hline Li [78] & 2014 & China & $\begin{array}{l}\text { Prospective } \\
\text { cohort study }\end{array}$ & 1225 & baPWV & $\begin{array}{l}\text { Significant both } \\
\text { with and without } \\
\text { presence of } \\
\text { metabolic syndrome }\end{array}$ & Yes \\
\hline Chung [77] & 2015 & Korea & $\begin{array}{c}\text { Cross-sectional } \\
\text { analysis }\end{array}$ & 2954 & CAVI & $\begin{array}{c}\text { Mild NAFLD: } \\
1.27(1.02-1.57) \\
\text { Moderate-severe } \\
\text { NAFLD: } 1.78 \\
(1.37-2.31)\end{array}$ & Yes \\
\hline
\end{tabular}

CAC - coronary artery calcium, AAC - abdominal aortic calcification, hSCRP - high-sensitivity C-reactive protein, CIMT - carotid intimamedia thickness, FMD - flow-mediated dilatation, baPWV - brachial-ankle pulse wave velocity, ALT - alanine aminotransferase, CAVI - cardioankle vascular index, NAFLD - non-alcoholic fatty liver disease. 
events and better predicts risk of stroke compared to myocardial infarction [63]. A cross-sectional study in an Indian population showed that subjects with NAFLD had a higher average and maximum CIMT than controls. The presence of NAFLD was an independent predictor of having a high average CIMT and high maximum CIMT after adjusting for obesity, the metabolic syndrome, insulin resistance, and lipid parameters [64]. Another case control study that compared 50 consecutive patients recruited from clinics with 40 matched healthy volunteers showed a statistically significant difference in CIMT between patients with $\mathrm{NASH}$, simple steatosis, and controls. The difference in groups was statistically significant after adjustment for age, sex, homeostatic model assessment-insulin resistance score, and the metabolic syndrome [65].

A large cross-sectional study on 8632 participants in China revealed a statistically significant higher CIMT in persons with NAFLD compared to those without NAFLD [66]. Logistic regression analysis showed that NAFLD conferred a $35 \%$ increased odds of elevated CIMT independent of conventional risk factors and the presence of the metabolic syndrome [66]. A larger meta-analysis included 4 studies [67-70]. This meta-analysis included 1,947 patients. Pathological CIMT was present in $35.1 \%$ of NAFLD patients compared to $21.8 \%$ of patients without NAFLD $(p<0.0001)$. In meta-regression analysis, age and body mass index did not alter statistical significance [71].

The cardioankle vascular index (CAVI) represents stiffness of the entire arterial segment from the aorta to the ankle $[72,73]$. Cardioankle vascular index reflects the progression of arteriosclerosis and is positively related to the severity of coronary atherosclerosis [74, 75]. Cardioankle vascular index also predicts carotid arteriosclerosis and stroke $[75,76]$. In a cross-sectional analysis of 2954 subjects, NAFLD was associated with a $42 \%$ increase in the risk of arterial stiffness [77]. The risk of arterial stiffness increased with the severity of NAFLD. The association was statistically significant after adjustment for other risk factors including body mass index, waist circumference, smoking status, diabetes, and hypertension [77].

Another measure of arterial stiffness is the brachial-ankle pulse wave velocity (baPWV). A prospective study included 728 men and 497 women free of hypertension and diabetes mellitus [78]. These subjects were followed for 5 years. During the study period, baPWV changes were significantly greater in subjects with NAFLD than in subjects without NAFLD. Multiple regression analysis revealed that NAFLD is an independent and significant predictor for changes of baPWV [78]. Anoth- er cross- sectional study in a Chinese population included 1296 non-obese, non-hypertensive and non-diabetic young and middle-aged subjects undergoing routine medical check-ups [79]. Subjects with NAFLD had a significantly higher level of baPWV than the controls $(1321 \pm 158 \mathrm{~cm} / \mathrm{s}$ vs. 1244 $\pm 154 \mathrm{~cm} / \mathrm{s} ; p<0.001)$. The prevalence of NAFLD was higher in the increased baPWV group versus the normal baPWV group (29.3\% vs. $16.9 \%$; $p<0.001)$. Multiple liner logistic regression analysis revealed that NAFLD was positively and independently associated with baPWV [79]. Another study also showed that subjects with NAFLD had a higher baPWV as compared to those without NAFLD $(1665 \pm 424 \mathrm{~cm} / \mathrm{s}$ vs. $1558 \pm 430 \mathrm{~cm} / \mathrm{s}$; $p<0.0001)$ [66]. Logistic regression revealed a $30 \%$ increased odds of elevated baPWV, independent of conventional risk factors and the presence of the metabolic syndrome [66].

\section{Non-alcoholic fatty liver disease and atherosclerotic cardiovascular disease}

Multiple epidemiological studies have linked NAFLD to increased cardiovascular disease risk [80, 81] (Table II). A prospective observational study included 1637 apparently healthy Japanese men and women followed for a period of 5 years [15]. Among 1221 participants available for outcome analysis, the incidence of atherosclerotic cardiovascular disease (CHD, ischemic stroke, and cerebral hemorrhage) was higher in subjects with NAFLD at baseline than those without NAFLD. Multivariate analyses indicated that NAFLD was a predictor of cardiovascular disease independent of conventional risk factors $(\mathrm{OR}=4.12 ; 95 \% \mathrm{Cl}$ : $1.58-10.75 ; p=0.004)$ [15].

A large prospective cohort study in a Chinese university hospital recruited 612 consecutive patients undergoing coronary angiography [16]. Coronary artery disease was present in $84.6 \%$ of the patients with NAFLD versus $64.1 \%$ without NAFLD. The association was statistically significant after adjusting for demographics and the metabolic syndrome $(\mathrm{OR}=2.31 ; 95 \% \mathrm{Cl}$ : $1.46-$ 3.64). During 87-week follow-up NAFLD did not predict cardiovascular mortality or morbidity [16]. The association of NAFLD and CAD was investigated in type 2 diabetic patients. A total of 273 diabetic patients without liver disease undergoing coronary CT angiography were enrolled [82]. Coronary artery disease was defined by the presence of coronary plaques, and significant CAD was defined as the presence of $\geq 50 \%$ stenosis in at least one coronary artery. No association was found between NAFLD and CAD. However, after adjustment for age, gender, obesity, hypertension, smoking status and serum low-density lipoprotein (LDL) cholesterol as coronary risk factors, NAFLD was 
Table II. Studies showing association of non-alcoholic fatty liver disease with coronary artery disease

\begin{tabular}{|c|c|c|c|c|c|c|}
\hline Author & Year & Country & Study design & Subjects & Findings & Risk estimates \\
\hline $\begin{array}{l}\text { Hamaguchi } \\
\text { [15] }\end{array}$ & 2007 & Japan & $\begin{array}{l}\text { Prospective } \\
\text { observational } \\
\text { study }\end{array}$ & $\begin{array}{c}1637 \\
(1221 \\
\text { available } \\
\text { for } \\
\text { analysis) }\end{array}$ & $\begin{array}{l}\text { 1. Higher incidence of ASCVD in } \\
\text { NAFLD subjects } \\
\text { 2. NAFLD was a predictor of ASCVD } \\
\text { independent of conventional risk } \\
\text { factors }\end{array}$ & $\begin{array}{l}\mathrm{OR}=4.12 \\
95 \% \mathrm{Cl} \\
1.58-10.75 \\
p=0.004\end{array}$ \\
\hline Wong [16] & 2011 & China & $\begin{array}{l}\text { Prospective } \\
\text { cohort study }\end{array}$ & 612 & $\begin{array}{l}\text { 1. CAD was more common in } \\
\text { patients with NAFLD } \\
\text { 2. NAFLD is associated with CAD } \\
\text { independent of other metabolic } \\
\text { factors }\end{array}$ & $\begin{array}{c}\mathrm{OR}=2.31 \\
95 \% \mathrm{Cl} \\
1.46-3.64\end{array}$ \\
\hline $\begin{array}{l}\text { Idilman } \\
\text { [82] }\end{array}$ & $\begin{array}{l}2007- \\
2010\end{array}$ & Turkey & $\begin{array}{l}\text { Cross- } \\
\text { sectional } \\
\text { retrospective } \\
\text { study }\end{array}$ & 273 & $\begin{array}{l}\text { NAFLD was associated with } \\
\text { significant CAD (defined as } \geq 50 \% \\
\text { stenosis, at least in one coronary } \\
\text { artery) in type } 2 \text { diabetics }\end{array}$ & $\begin{array}{c}\mathrm{OR}=2.128 \\
95 \% \mathrm{Cl}: \\
1.035-4.377\end{array}$ \\
\hline Alper [83] & 2008 & Turkey & $\begin{array}{l}\text { Prospective } \\
\text { cohort study }\end{array}$ & 80 & $\begin{array}{l}\text { 1. More vessels involved among } \\
\text { patients with NAFLD as compared } \\
\text { to patients without NAFLD } \\
\text { 2. NAFLD is associated with more } \\
\text { severe CAD }\end{array}$ & $\begin{array}{c}\text { Number of } \\
\text { vessels } \\
(2.5 \pm 0.9 \text { vs. } \\
1.0 \pm 1.0 \\
p<0.001) \\
\text { CAD severity } \\
\text { scores } \\
(90.2 \pm 40.0 \text { vs. } \\
36.4 \pm 28.9 \\
p<0.001)\end{array}$ \\
\hline Acikel [84] & 2009 & Turkey & $\begin{array}{l}\text { Cross- } \\
\text { sectional } \\
\text { analysis }\end{array}$ & 355 & $\begin{array}{l}\text { NAFLD has an independent effect } \\
\text { on CAD and Gensini score }\end{array}$ & $\begin{array}{c}\text { CAD }(\mathrm{OR}= \\
2.58 ; p<0.01) \\
\text { Gensini Score } \\
(\mathrm{OR}=2.02 \\
\quad p<0.05)\end{array}$ \\
\hline Sun [85] & 2011 & China & $\begin{array}{l}\text { Cross- } \\
\text { sectional } \\
\text { analysis }\end{array}$ & 542 & $\begin{array}{l}\text { 1. NAFLD independently increased } \\
\text { the risk for CAD } \\
\text { 2. NAFLD was significantly more } \\
\text { common in patients as CAD } \\
\text { severity increased }\end{array}$ & $\begin{array}{c}\mathrm{OR}=7.585 \\
95 \% \mathrm{Cl} \\
4.617-12.461\end{array}$ \\
\hline Arslan [88] & 2012 & Turkey & $\begin{array}{l}\text { Cross-sectional } \\
\text { analysis }\end{array}$ & 151 & $\begin{array}{l}\text { 1. NAFLD was more prevalent } \\
\text { in patients with poor coronary } \\
\text { collateral circulation } \\
\text { 2. Mean Rentrop collateral score } \\
\text { was significantly lower in patients } \\
\text { with NAFLD }\end{array}$ & $\begin{array}{l}\text { 1. } 82.9 \% \text { vs. } \\
\quad 49.4 \% \\
p<0.001 \\
\text { 2. } 1.2 \pm 1.2 \text { vs. } \\
2.1 \pm 0.9 \\
p<0.001\end{array}$ \\
\hline $\begin{array}{l}\text { Targher } \\
{[14]}\end{array}$ & $\begin{array}{l}2000- \\
2005\end{array}$ & Italy & $\begin{array}{l}\text { Prospective } \\
\text { nested case- } \\
\text { control study }\end{array}$ & 2103 & $\begin{array}{l}\text { NAFLD was significantly associated } \\
\text { with increased cardiovascular } \\
\text { disease among type } 2 \text { diabetics } \\
\text { independent of traditional } \\
\text { risk factors and the metabolic } \\
\text { syndrome }\end{array}$ & $\begin{array}{l}\text { OR }=1.84 \\
95 \% \mathrm{Cl} \\
1.4-2.1 \\
p<0.001\end{array}$ \\
\hline Pisto [13] & $\begin{array}{c}1991- \\
2009\end{array}$ & Finland & $\begin{array}{l}\text { Population } \\
\text { based } \\
\text { randomly } \\
\text { recruited } \\
\text { cohort }\end{array}$ & 988 & $\begin{array}{l}\text { Severe liver fat content predicted } \\
\text { the risk of future cardiovascular } \\
\text { events after adjustment for age, } \\
\text { gender, and study group }\end{array}$ & $\begin{array}{c}\mathrm{HR}=1.92 ; \\
95 \% \mathrm{Cl}: \\
1.32-2.80\end{array}$ \\
\hline
\end{tabular}

ASCVD - atherosclerotic cardiovascular disease, NAFLD - non-alcoholic fatty liver disease, CAD - coronary artery disease.

associated with significant CAD in type 2 diabetics $(\mathrm{OR}=2.128 ; 95 \% \mathrm{Cl}: 1.035-4.377)$ [82].

A prospective study in 80 patients with the metabolic syndrome undergoing coronary angiography evaluated the association between NAFLD and CAD severity [83]. Coronary angiogra- phy showed involvement of more vessels $(2.5 \pm 0.9$ vs. $1.0 \pm 1.0 ; p<0.001)$ and more severe CAD severity scores (Gensini scores, $90.2 \pm 40.0$ vs. $36.4 \pm 28.9$; $p<0.001)$ among patients with NAFLD. In multivariate regression analysis, NAFLD was the only independent factor affecting CAD severity score 
[83]. Another study investigated cross-sectional analysis of 355 patients undergoing coronary angiography and showed a similar conclusion [84]. Univariate analysis showed that the presence of NAFLD has independent effects on CAD $(O R=2.58$; $p<0.01)$ and also independently affects Gensini score $(O R=2.02 ; p<0.05)$ [84]. Sun et al. enrolled 542 patients planned to undergo coronary angiography [85]. Abdominal computed tomography (CT) was performed before coronary angiography to detect NAFLD. Logistic regression analysis showed that the presence of NAFLD independently increased the risk of CAD seen on coronary angiography $(\mathrm{OR}=7.585 ; 95 \% \mathrm{Cl}$ : 4.617-12.461). Non-alcoholic fatty liver disease was seen significantly more common in patients as the CAD severity increased [85].

Coronary collateral development has been shown to improve survival in patients with CAD [86]. The presence of the metabolic syndrome and associated insulin resistance have been shown to be associated with poor collateral development [87]. Arslan et al. enrolled 151 consecutive non-diabetic patients with stable angina pectoris with more than $95 \%$ stenosis in at least one major coronary artery [76]. Non-alcoholic fatty liver disease was more prevalent in patients with poor collateral development ( $82.9 \%$ vs. $49.4 \% ; p<0.001)$. The mean Rentrop collateral score was significantly lower in patients with NAFLD (1.2 \pm 1.2 vs. 2.1 $\pm 0.9 ; p<0.001$ ). Non-alcoholic fatty liver disease was significantly related to poor circulation $(\mathrm{OR}=$ 6.20; 2.61-14.75) after logistic regression analysis was performed using factors associated with poor collateral development [88].

Targher et al. carried out a prospective-nested case-control study in 2103 type 2 diabetics free of cardiovascular disease at baseline [14]. During a 5-year follow-up, 248 participants subsequently developed nonfatal cardiac event, ischemic stroke or cardiovascular death. Four hundred ninety-six subjects that remained free of diagnosed cardiovascular disease were selected as controls. Non-alcoholic fatty liver disease was significantly associated with an increased atherosclerotic cardiovascular disease risk $(\mathrm{OR}=1.84 ; 95 \% \mathrm{Cl}$ : $1.4-$ $2.1 ; p<0.001)$ after adjustment for age, sex, smoking history, diabetes duration, hemoglobin $A_{1 c}$, LDL cholesterol, liver enzymes, and use of medications. The risk was attenuated but stayed statistically significant after adjustment for the metabolic syndrome [14]. Pisto et al. followed 988 Finnish participants from 1991-2009. Patients were divided in three groups based on liver fat content. During the follow-up period, $13.5 \%$ of participants with non-fatty liver, $24.2 \%$ with moderate liver fat content, and $29.2 \%$ with severe fatty liver experienced a cardiovascular event $(p<0.001)$. Severe liver fat content predicted the risk of future cardiovascular event when adjusted for age, gender, and study group $(H R=1.92$; 95\% Cl: 1.32-2.80). The risk remained statistically significant $(\mathrm{HR}=1.74,95 \% \mathrm{Cl}: 1.16-2.63)$ after further adjustment for smoking, alcohol consumption, LDL cholesterol, body mass index, and systolic blood pressure, but disappeared after further adjustment for the QUICKI (Quantitative Insulin Sensitivity Check Index) [13].

Non-alcoholic fatty liver disease is associated with a higher average CIMT, maximum CIMT and presence of pathological CIMT $[64,65,71]$. Carotid intima-media thickness predicts the risk of future atherosclerotic cardiovascular disease including stroke [63]. However, there are inconclusive data linking NAFLD with stroke. A cross-sectional study studied the association of acute ischemic stroke with biochemical markers of NAFLD [89]. Elevated alanine aminotransferase (ALT), $\geq 95^{\text {th }}$ percentile was used as the criterion for the biochemical presence of inflammatory NAFLD. The odds ratio for stroke in patients with an elevated ALT was 3.5 (95\% Cl: $1.7-7.6)$ and it was 3.3 (95\% Cl: 1.3-8.4) after adjustment for age, sex, current smoking, current heavy alcohol intake, history of hypertension, atrial fibrillation, LDL cholesterol, serum glucose, and serum creatinine [89]. Another case control study included 110 brain magnetic resonance imaging confirmed ischemic stroke patients and 110 age-and sex-matched controls [90]. Liver ultrasonography was performed to detect NAFLD. Non-alcoholic fatty liver disease was found in $47(42.7 \%)$ of ischemic stroke patients and 25 (22.7\%) of controls. After adjusting for age and sex, NAFLD was significantly associated with ischemic stroke $(\mathrm{OR}=2.15 ; 95 \% \mathrm{Cl}: 1.25-3.71)$. However, the association lost statistical significance after adjusting for confounding risk factors including body mass index, waist circumference, smoking, and diabetes mellitus [90].

\section{Treatment of non-alcoholic fatty liver disease}

Treatment of NAFLD risk factors is the first line treatment strategy for NAFLD. Various lifestyle modifications have shown benefit in NAFLD. These include weight reduction [91, 92], reduced calorie intake, exercise alone even without weight loss [48-50]. A weight reduction achieved by bariatric procedures has also shown significant benefit in NAFLD [44-46].

Several studies have studied the effectiveness of metformin in NAFLD [93]. The results have been inconsistent with some studies showing benefit $[94,95]$, while others not showing any significant benefit $[96,97]$. Based on available evidence, current guidelines do not recommend metformin as a specific treatment for liver disease in patients with NAFLD [1]. 
Thiazolidinediones (TZDs) increase hepatic lipogenesis and insulin sensitivity by activating peroxisomal proliferator activated receptor- $\gamma$ (PPAR- $\gamma$ ) [98]. Among TZDs, rosiglitazone and pioglitazone have been studied the most. In a randomized placebo-controlled clinical trial, rosiglitazone improved steatosis and transaminase level despite weight gain at the end of 1 year [99]. Longer therapy did not show additional improvement in steatosis despite a maintained effect on insulin sensitivity and transaminase levels [100]. Pioglitazone also showed significant improvement in fibrosis and hepatocellular injury after 12 months of treatment [101]. The results of another larger study did not reach statistical significance [102]. Overall evidence favors use of TZDs; however, caution should be taken in view of their cardiovascular adverse effects.

Liraglutide is a long-acting human glucagon-like peptide-1 (GLP-1) analog. Apart from glucose-reducing effects, liraglutide is associated with decreased level of pro-inflammatory cytokines [103]. In a phase 2 clinical trial, liragltide use was associated with greater odds of resolution of NASH (relative risk 4.3; $95 \% \mathrm{Cl}$ : 1.0-17.7; $p=0.019$ ) [104]. Another study involving 8 months of liraglutide use in patients with type 2 diabetes mellitus and NAFLD has shown significantly reduced CIMT, a marker of subclinical atherosclerosis [105]. This effect was independent of glucometabolic changes. Further studies are needed to validate these findings and to advocate use of liraglutide in NAFLD.

Among lipid lowering drugs, statins and polyunsaturated fatty acids (PUFA) have shown benefit in NAFLD. In a cross sectional study of 2578 patients undergoing ultrasound, statin use of more than 2 years duration and body mass index more than $27.5 \mathrm{~kg} / \mathrm{m}^{2}$ was associated with lower prevalence of steatosis $(\mathrm{OR}=0.30,95 \% \mathrm{Cl}$ : 0.11-0.81) [106]. Clinical studies with atorvastatin have shown improvement in steatosis [107] and delayed progression of NAFL to NASH [108]. The current guidelines allow use of statins to treat dyslipidemia in patients with NAFLD but do not recommend their use to specifically treat NAFLD [1]. N-3 PUFA (omega-3 fatty acids) have also shown promising results in patients with NAFLD [109]. Based on current evidence, they are not recommended to specifically treat NAFLD, but may be considered as first line agents to treat hypertriglyceridemia in patients with NAAFLD [1].

Oxidative stress is one of the important hits in NAFLD pathogenesis. Anti-oxidant property of Vitamin $E$ has been studied as a possible therapeutic intervention with some success [102]. It is recommended as a first-line pharmacotherapy for biopsy-proven NASH in non-diabetic patients [1].
Other potential treatments include $\mathrm{N}$-acetyl cysteine, vitamin D, ursodeoxycholic acid and pentoxifylline [110]. Further studies are needed to assess the therapeutic effects of these agents in NAFLD.

\section{Conclusions}

The majority of the studies discussed indicate that NAFLD is associated with cardiovascular disease. NAFLD affects multiple aspects of cardiovascular diseases. Non-alcoholic fatty liver disease is associated with subclinical atherosclerosis and arterial stiffness. The popular notion used to be that this association is due to shared risk factors such as obesity, metabolic syndrome, and diabetes mellitus among others. However, multiple studies have proved this association to be independent of the metabolic syndrome and traditional cardiovascular risk factors. These studies used CAC and CIMT as markers of subclinical atherosclerosis while CIMT and baPWV were used as markers of arterial stiffness (Table I). One of the prospective studies also showed that NAFLD independently and significantly predicted changes in baPWV [78].

Additionally the study by Chung et al. also showed association between NAFLD and subclinical atherosclerosis in NAFLD severity-dependent manner [77]. Multivariate analysis showed a severity-dependent relationship between NAFLD and arterial stiffness (moderate-severe NAFLD: $\mathrm{OR}=1.97,95 \% \mathrm{Cl}: 1.28-3.01, p$ for trend $=0.002$ ) in age group less than 55 years [77]. A study evaluating lipid profile among patients with NAFLD showed that NASH patients had lower levels of larger LDL1 and increased levels of small dense LDL3 and LDL4 compared to patients with simple steatosis [111]. This deranged lipid profile may partly explain increased risk of atherosclerosis and cardiovascular disease in patients with NASH compared to NAFL patients [112].

Epidemiological data exist to link CAD directly to NAFLD. These studies have shown a higher incidence of $C A D$, a higher prevalence of $C A D$, greater severity of $C A D$, a higher risk of future cardiovascular event, and increased atherosclerotic cardiovascular disease among subjects with NAFLD as compared to subjects without NAFLD (Table II). Most of these studies were adjusted for the presence of conventional risk factors shared by NAFLD and CAD. Physicians treating NAFLD should be cognizant of these associations and should actively look out for symptoms of CAD in this population, facilitating early therapeutic interventions.

Arslan et al. showed that NAFLD was associated with poor coronary collateral development [88]. Insulin resistance [59, 80], oxidative stress [9], worsening inflammatory state $[9,62]$, and endothelial dysfunction [113] have all been implicated in the pathogenesis of cardiovascular disease in 
NAFLD. The current understanding is that insulin resistance is responsible for resistance to the antilipolytic effect of insulin and combined with visceral and pathological ectopic fat accumulation of NAFLD lead to an increased availability of free fatty acids [80]. The increased availability of free fatty with ongoing chronic subclinical inflammation, increased oxidative stress, and endothelial dysfunction promotes atherosclerosis and a dysfunctional physiological state with poor cardiovascular outcomes [80, 81]. Even though strong epidemiological evidence is available linking NAFLD with subclinical atherosclerosis and atherosclerotic vascular disease, our knowledge of the biochemical pathways contributing to this association is incomplete. More studies are needed to understand the underlying biochemical pathways and markers responsible for above findings which could lead to development of needed therapeutic interventions.

\section{Conflict of interest}

The authors declare no conflict of interest.

\section{References}

1. Chalasani N, Younossi Z, Lavine JE, et al. The diagnosis and management of non-alcoholic fatty liver disease: Practice guideline by the American Association for the Study of Liver Diseases, American College of Gastroenterology, and the American Gastroenterological Association. Am J Gastroenterol 2012; 107: 811-26.

2. Saponaro C, Gaggini M, Gastaldelli A. Nonalcoholic fatty liver disease and type 2 diabetes: common pathophysiologic mechanisms. Curr Diab Rep 2015; 15: 607.

3. Caturelli E, Squillante MM, Andriulli A, et al. Hypoechoic lesions in the 'bright liver': a reliable indicator of fatty change. A prospective study. J Gastroenterol Hepatol 1992; 7: 469-72.

4. Saadeh S, Younossi ZM, Remer EM, et al. The utility of radiological imaging in nonalcoholic fatty liver disease. Gastroenterology 2002; 123: 745-50.

5. Baffy G, Brunt EM, Caldwell SH. Hepatocellular carcinoma in non-alcoholic fatty liver disease: an emerging menace. J Hepatol 2012; 56: 1384-91.

6. Angulo P, Hui JM, Marchesini G, et al. The NAFLD fibrosis score: a noninvasive system that identifies liver fibrosis in patients with NAFLD. Hepatology 2007; 45: 846-54.

7. Wieckowska A, Zein NN, Yerian LM, Lopez AR, McCullough AJ, Feldstein AE. In vivo assessment of liver cell apoptosis as a novel biomarker of disease severity in nonalcoholic fatty liver disease. Hepatology 2006; 44: 27-33.

8. Almeda-Valdés P, Cuevas-Ramos D, Aguilar-Salinas CA. Metabolic syndrome and non-alcoholic fatty liver disease. Ann Hepatol 2009; 8 Suppl 1: S18-24.

9. Fargion S, Porzio M, Fracanzani AL. Nonalcoholic fatty liver disease and vascular disease: state-of-the-art. World J Gastroenterol 2014; 20: 13306-24.

10. Adams LA, Lymp JF, St Sauver J, et al. The natural history of nonalcoholic fatty liver disease: a population-based cohort study. Gastroenterology 2005; 129: 113-21.
11. Ong JP, Pitts A, Younossi ZM. Increased overall mortality and liver-related mortality in non-alcoholic fatty liver disease. J Hepatol 2008; 49: 608-12.

12. Vernon G, Baranova A, Younossi ZM. Systematic review: the epidemiology and natural history of non-alcoholic fatty liver disease and non-alcoholic steatohepatitis in adults. Aliment Pharmacol Ther 2011; 34: 274-85.

13. Pisto P, Santaniemi M, Bloigu R, Ukkola O, Kesäniemi YA. Fatty liver predicts the risk for cardiovascular events in middle-aged population: a population-based cohort study. BMJ Open 2014; 4: e004973.

14. Targher G, Bertolini L, Poli F, et al. Nonalcoholic fatty liver disease and risk of future cardiovascular events among type 2 diabetic patients. Diabetes 2005; 54: 3541-6.

15. Hamaguchi M, Kojima T, Takeda N, et al. Nonalcoholic fatty liver disease is a novel predictor of cardiovascular disease. World J Gastroenterol 2007; 13: 1579-84.

16. Wong VW, Wong GL, Yip GW, et al. Coronary artery disease and cardiovascular outcomes in patients with non-alcoholic fatty liver disease. Gut 2011; 60: 1721-7.

17. Whalley S, Puvanachandra P, Desai A, Kennedy $\mathrm{H}$. Hepatology outpatient service provision in secondary care: a study of liver disease incidence and resource costs. Clin Med (Lond) 2007; 7: 119-24.

18. Hamaguchi M, Kojima T, Takeda N, et al. The metabolic syndrome as a predictor of nonalcoholic fatty liver disease. Ann Intern Med 2005; 143: 722-8.

19. Machado M, Marques-Vidal P, Cortez-Pinto H. Hepatic histology in obese patients undergoing bariatric surgery. J Hepatol 2006; 45: 600-6.

20. Leite NC, Salles GF, Araujo AL, Villela-Nogueira CA, Cardoso CR. Prevalence and associated factors of non-alcoholic fatty liver disease in patients with type-2 diabetes mellitus. Liver Int 2009; 29: 113-9.

21. Poanta LI, Albu A, Fodor D. Association between fatty liver disease and carotid atherosclerosis in patients with uncomplicated type 2 diabetes mellitus. Med UItrason 2011; 13: 215-9.

22. Assy N, Kaita K, Mymin D, Levy C, Rosser B, Minuk G. Fatty infiltration of liver in hyperlipidemic patients. Dig Dis Sci 2000; 45: 1929-34.

23. Day CP, James OF. Steatohepatitis: a tale of two "hits"? Gastroenterology 1998; 114: 842-5.

24. Bugianesi E, Gastaldelli A, Vanni E, et al. Insulin resistance in non-diabetic patients with non-alcoholic fatty liver disease: sites and mechanisms. Diabetologia 2005; 48: 634-42.

25. Charlton M. Nonalcoholic fatty liver disease: a review of current understanding and future impact. Clin Gastroenterol Hepatol 2004; 2: 1048-58.

26. Kantartzis K, Peter A, Machicao F, et al. Dissociation between fatty liver and insulin resistance in humans carrying a variant of the patatin-like phospholipase 3 gene. Diabetes 2009; 58: 2616-23.

27. Amaro A, Fabbrini E, Kars M, et al. Dissociation between intrahepatic triglyceride content and insulin resistance in familial hypobetalipoproteinemia. Gastroenterology 2010; 139: 149-53.

28. Visser ME, Lammers NM, Nederveen AJ, et al. Hepatic steatosis does not cause insulin resistance in people with familial hypobetalipoproteinaemia. Diabetologia 2011; 54: 2113-21.

29. Videla LA, Rodrigo R, Araya J, Poniachik J. Oxidative stress and depletion of hepatic long-chain polyunsaturated fatty acids may contribute to nonalcoholic fatty liver disease. Free Radic Biol Med 2004; 37: 1499-507. 
30. Tilg $\mathrm{H}$, Moschen AR. Evolution of inflammation in nonalcoholic fatty liver disease: the multiple parallel hits hypothesis. Hepatology 2010; 52: 1836-46.

31. Yilmaz Y. Review article: is non-alcoholic fatty liver disease a spectrum, or are steatosis and non-alcoholic steatohepatitis distinct conditions? Aliment Pharmacol Ther 2012; 36: 815-23.

32. Tilg $\mathrm{H}$. The role of cytokines in non-alcoholic fatty liver disease. Dig Dis 2010; 28: 179-85.

33. Hotamisligil GS, Shargill NS, Spiegelman BM. Adipose expression of tumor necrosis factor-alpha: direct role in obesity-linked insulin resistance. Science 1993; 259: 87-91.

34. Uysal KT, Wiesbrock SM, Marino MW, Hotamisligil GS. Protection from obesity-induced insulin resistance in mice lacking TNF-alpha function. Nature 1997; 389: 610-4.

35. Haukeland JW, Damås JK, Konopski Z, et al. Systemic inflammation in nonalcoholic fatty liver disease is characterized by elevated levels of CCL2. J Hepatol 2006; 44: 1167-74.

36. Wieckowska A, Papouchado BG, Li Z, Lopez R, Zein NN, Feldstein AE. Increased hepatic and circulating interleukin-6 levels in human nonalcoholic steatohepatitis. Am J Gastroenterol 2008; 103: 1372-9.

37. Hui JM, Hodge A, Farrell GC, Kench JG, Kriketos A, George J. Beyond insulin resistance in NASH: TNF-alpha or adiponectin? Hepatology 2004; 40: 46-54.

38. Zhao L, Fu Z, Wu J, et al. Inflammation-induced microvascular insulin resistance is an early event in diet-induced obesity. Clin Sci (Lond) 2015; 129: 1025-36.

39. Milić S, Lulić D, Štimac D. Non-alcoholic fatty liver disease and obesity: biochemical, metabolic and clinical presentations. World J Gastroenterol 2014; 20: 9330-7.

40. Kahn BB, Flier JS. Obesity and insulin resistance. J Clin Invest 2000; 106: 473-81.

41. Beck-Nielsen H, Pedersen O, Lindskov HO. Normalization of the insulin sensitivity and the cellular insulin binding during treatment of obese diabetics for one year. Acta Endocrinol (Copenh) 1979; 90: 103-12.

42. Long SD, O’Brien K, MacDonald KG, et al. Weight loss in severely obese subjects prevents the progression of impaired glucose tolerance to type II diabetes. A longitudinal interventional study. Diabetes Care 1994; 17: 372-5.

43. Choudhary NS, Saraf N, Saigal S, et al. Rapid reversal of liver steatosis with life style modification in highly motivated liver donors. J Clin Exp Hepatol 2015; 5: 123-6.

44. Bower G, Athanasiou T, Isla AM, et al. Bariatric surgery and nonalcoholic fatty liver disease. Eur J Gastroenterol Hepatol 2015; 27: 755-68.

45. Chavez-Tapia NC, Tellez-Avila Fl, Barrientos-Gutierrez T, Mendez-Sanchez N, Lizardi-Cervera J, Uribe $M$. Bariatric surgery for non-alcoholic steatohepatitis in obese patients. Cochrane Database Syst Rev 2010; 1: CD007340.

46. Mathurin P, Hollebecque A, Arnalsteen L, et al. Prospective study of the long-term effects of bariatric surgery on liver injury in patients without advanced disease. Gastroenterology 2009; 137: 532-40.

47. Furuya CK, de Oliveira CP, de Mello ES, et al. Effects of bariatric surgery on nonalcoholic fatty liver disease: preliminary findings after 2 years. J Gastroenterol Hepatol 2007; 22: 510-4.

48. Oliveira CP, de Lima Sanches P, de Abreu-Silva EO, Marcadenti A. Nutrition and physical activity in nonalcoholic fatty liver disease. J Diabetes Res 2016; 2016: 4597246.
49. Kwak MS, Kim D, Chung GE, Kim W, Kim YJ, Yoon JH. Role of physical activity in nonalcoholic fatty liver disease in terms of visceral obesity and insulin resistance. Liver Int 2015; 35: 944-52.

50. Bae JC, Suh S, Park SE, et al. Regular exercise is associated with a reduction in the risk of NAFLD and decreased liver enzymes in individuals with NAFLD independent of obesity in Korean adults. PLoS One 2012; 7: e46819.

51. Zhang C, Guo L. [Interaction of polymorphisms of monocyte chemoattractant protein-1 receptor CCR2 gene 190A/G, nicotinamide adenine dinucleotide phosphate oxidase subunit p22phox gene C242T and cigarette smoking increases the risk of nonalcoholic fatty liver disease]. Wei Sheng Yan Jiu 2015; 44: 730-7.

52. Zhang C, Guo L, Guo X. [Interaction of polymorphisms of leptin receptor gene Gln223Arg, MnSOD9Ala/Val genes and smoking in nonalcoholic fatty liver disease]. Wei Sheng Yan Jiu 2014; 43: 724-31.

53. Zhang C, Guo L. [Correlation of polymorphisms of adiponectin receptor 2 gene $+33371 \mathrm{Gln} / \mathrm{Arg}$, cytochrome P4502E1 gene Rsa I and smoking with nonalcoholic fatty liver disease]. Nan Fang Yi Ke Da Xue Xue Bao 2014; 34: 1481-7.

54. Swinburn BA. Effect of dietary lipid on insulin action. Clinical studies. Ann N Y Acad Sci 1993; 683: 102-9.

55. Wiedemann MS, Wueest S, Item F, Schoenle EJ, Konrad D. Adipose tissue inflammation contributes to shortterm high-fat diet-induced hepatic insulin resistance. Am J Physiol Endocrinol Metab 2013; 305: E388-95.

56. Pan X, Wang P, Luo J, et al. Adipogenic changes of hepatocytes in a high-fat diet-induced fatty liver mice model and non-alcoholic fatty liver disease patients. Endocrine 2015; 48: 834-47.

57. Targher G. Nonalcoholic fatty liver disease and atherosclerosis. Arterioscler Thromb Vasc Biol 2005; 25: e117; author reply e117-8.

58. Greenland P, Bonow RO, Brundage BH, et al. ACCF/AHA 2007 clinical expert consensus document on coronary artery calcium scoring by computed tomography in global cardiovascular risk assessment and in evaluation of patients with chest pain: a report of the American College of Cardiology Foundation Clinical Expert Consensus Task Force (ACCF/AHA Writing Committee to Update the 2000 Expert Consensus Document on Electron Beam Computed Tomography) developed in collaboration with the Society of Atherosclerosis Imaging and Prevention and the Society of Cardiovascular Computed Tomography. J Am Coll Cardiol 2007; 49: 378-402.

59. Sung KC, Wild SH, Kwag HJ, Byrne CD. Fatty liver, insulin resistance, and features of metabolic syndrome: relationships with coronary artery calcium in 10,153 people. Diabetes Care 2012; 35: 2359-64.

60. Santos RD, Nasir K, Conceição RD, Sarwar A, Carvalho JA, Blumenthal RS. Hepatic steatosis is associated with a greater prevalence of coronary artery calcification in asymptomatic men. Atherosclerosis 2007; 194: 517-9.

61. VanWagner LB, Ning $H$, Lewis CE, et al. Associations between nonalcoholic fatty liver disease and subclinical atherosclerosis in middle-aged adults: the Coronary Artery Risk Development in Young Adults Study. Atherosclerosis 2014; 235: 599-605.

62. Al Rifai M, Silverman MG, Nasir K, et al. The association of nonalcoholic fatty liver disease, obesity, and metabolic syndrome, with systemic inflammation and 
subclinical atherosclerosis: the Multi-Ethnic Study of Atherosclerosis (MESA). Atherosclerosis 2015; 239: 629-33.

63. Johnsen SH, Mathiesen EB. Carotid plaque compared with intima-media thickness as a predictor of coronary and cerebrovascular disease. Curr Cardiol Rep 2009; 11: 21-7.

64. Thakur ML, Sharma S, Kumar A, et al. Nonalcoholic fatty liver disease is associated with subclinical atherosclerosis independent of obesity and metabolic syndrome in Asian Indians. Atherosclerosis 2012; 223: 507-11.

65. Targher G, Bertolini L, Padovani R, Zoppini G, Zenari L, Falezza G. Associations between liver histology and carotid intima-media thickness in patients with nonalcoholic fatty liver disease. Arterioscler Thromb Vasc Biol 2005; 25: 2687-8.

66. Huang Y, Bi Y, Xu M, et al. Nonalcoholic fatty liver disease is associated with atherosclerosis in middle-aged and elderly Chinese. Arterioscler Thromb Vasc Biol 2012; 32: 2321-6.

67. Kang JH, Cho KI, Kim SM, et al. Relationship between nonalcoholic fatty liver disease and carotid artery atherosclerosis beyond metabolic disorders in non-diabetic patients. J Cardiovasc Ultrasound 2012; 20: 126-33.

68. Agarwal AK, Jain V, Singla S, et al. Prevalence of non-alcoholic fatty liver disease and its correlation with coronary risk factors in patients with type 2 diabetes. J Assoc Physicians India 2011; 59: 351-4.

69. Wang CC, Lin SK, Tseng YF, et al. Elevation of serum aminotransferase activity increases risk of carotid atherosclerosis in patients with non-alcoholic fatty liver disease. J Gastroenterol Hepatol 2009; 24: 1411-6.

70. Kim HC, Kim DJ, Huh KB. Association between nonalcoholic fatty liver disease and carotid intima-media thickness according to the presence of metabolic syndrome. Atherosclerosis 2009; 204: 521-5.

71. Ampuero J, Gallego-Durán R, Romero-Gómez M. Association of NAFLD with subclinical atherosclerosis and coronary-artery disease: meta-analysis. Rev Esp Enferm Dig 2015; 107: 10-6.

72. Saiki A, Sato $Y$, Watanabe R, et al. The role of a novel arterial stiffness parameter, Cardio-Ankle Vascular Index (CAVI), as a surrogate marker for cardiovascular diseases. J Atheroscler Thromb 2016; 23: 155-68.

73. Shirai K, Hiruta N, Song M, et al. Cardio-ankle vascular index (CAVI) as a novel indicator of arterial stiffness: theory, evidence and perspectives. J Atheroscler Thromb 2011; 18: 924-38.

74. Nakamura K, Tomaru T, Yamamura S, Miyashita Y, Shirai K, Noike H. Cardio-ankle vascular index is a candidate predictor of coronary atherosclerosis. Circ J 2008; 72: 598-604

75. Izuhara M, Shioji K, Kadota S, et al. Relationship of cardio-ankle vascular index (CAVI) to carotid and coronary arteriosclerosis. Circ J 2008; 72: 1762-7.

76. Suzuki J, Sakakibara R, Tomaru T, et al. Stroke and cardio-ankle vascular stiffness index. J Stroke Cerebrovasc Dis 2013; 22: 171-5.

77. Chung GE, Choi SY, Kim D, et al. Nonalcoholic fatty liver disease as a risk factor of arterial stiffness measured by the cardioankle vascular index. Medicine (Baltimore) 2015; 94: e654.

78. Li N, Zhang GW, Zhang JR, et al. Non-alcoholic fatty liver disease is associated with progression of arterial stiffness. Nutr Metab Cardiovasc Dis 2015; 25: 218-23.

79. Yu XY, Zhao Y, Song XX, Song ZY. Association between non-alcoholic fatty liver disease and arterial stiffness in the non-obese, non-hypertensive, and non-diabetic young and middle-aged Chinese population. J Zhejiang Univ Sci B 2014; 15: 879-87.

80. Gaggini M, Morelli M, Buzzigoli E, DeFronzo RA, Bugianesi E, Gastaldelli A. Non-alcoholic fatty liver disease (NAFLD) and its connection with insulin resistance, dyslipidemia, atherosclerosis and coronary heart disease. Nutrients 2013; 5: 1544-60.

81. Bhatia LS, Curzen NP, Calder PC, Byrne CD. Non-alcoholic fatty liver disease: a new and important cardiovascular risk factor? Eur Heart J 2012; 33: 1190-200.

82. Idilman IS, Akata D, Hazirolan T, Doganay Erdogan B, Aytemir K, Karcaaltincaba M. Nonalcoholic fatty liver disease is associated with significant coronary artery disease in type 2 diabetic patients: a computed tomography angiography study 2. J Diabetes 2015; 7: 279-86.

83. Alper AT, Hasdemir H, Sahin S, et al. The relationship between nonalcoholic fatty liver disease and the severity of coronary artery disease in patients with metabolic syndrome. Turk Kardiyol Dern Ars 2008; 36: 376-81.

84. Açikel M, Sunay S, Koplay M, Gündoğdu F, Karakelleoğlu S. Evaluation of ultrasonographic fatty liver and severity of coronary atherosclerosis, and obesity in patients undergoing coronary angiography. Anadolu Kardiyol Derg 2009; 9: 273-9.

85. Sun L, Lü SZ. Association between non-alcoholic fatty liver disease and coronary artery disease severity. Chin Med J (Engl) 2011; 124: 867-72.

86. Hansen JF. Coronary collateral circulation: clinical significance and influence on survival in patients with coronary artery occlusion. Am Heart J 1989; 117: 290-5.

87. Kornowski R. Collateral formation and clinical variables in obstructive coronary artery disease: the influence of hypercholesterolemia and diabetes mellitus. Coron Artery Dis 2003; 14: 61-4.

88. Arslan U, Kocaoğlu I, Balcı M, Duyuler S, Korkmaz A. The association between impaired collateral circulation and non-alcoholic fatty liver in patients with severe coronary artery disease. J Cardiol 2012; 60: 210-4.

89. Ying I, Saposnik G, Vermeulen MJ, Leung A, Ray JG. Nonalcoholic fatty liver disease and acute ischemic stroke. Epidemiology 2011; 22: 129-30.

90. Moshayedi H, Ahrabi R, Mardani A, Sadigetegad S, Farhudi M. Association between non-alcoholic fatty liver disease and ischemic stroke. Iran J Neurol 2014; 13: 144-8.

91. Petersen KF, Dufour S, Befroy D, Lehrke M, Hendler RE, Shulman GI. Reversal of nonalcoholic hepatic steatosis, hepatic insulin resistance, and hyperglycemia by moderate weight reduction in patients with type 2 diabetes. Diabetes 2005; 54: 603-8.

92. Huang MA, Greenson JK, Chao C, et al. One-year intense nutritional counseling results in histological improvement in patients with non-alcoholic steatohepatitis: a pilot study. Am J Gastroenterol 2005; 100: 1072-81.

93. Li Y, Liu L, Wang B, Wang J, Chen D. Metformin in non-alcoholic fatty liver disease: a systematic review and meta-analysis. Biomed Rep 2013; 1: 57-64.

94. Marchesini G, Brizi M, Bianchi G, Tomassetti S, Zoli M, Melchionda N. Metformin in non-alcoholic steatohepatitis. Lancet 2001; 358: 893-94.

95. Bugianesi E, Gentilcore E, Manini R, et al. A randomized controlled trial of metformin versus vitamin $E$ or 
prescriptive diet in nonalcoholic fatty liver disease. Am J Gastroenterol 2005; 100: 1082-90.

96. Idilman R, Mizrak D, Corapcioglu D, et al. Clinical trial: insulin-sensitizing agents may reduce consequences of insulin resistance in individuals with non-alcoholic steatohepatitis. Aliment Pharmacol Ther 2008; 28: 200-8.

97. Shields WW, Thompson KE, Grice GA, Harrison SA, Coyle WJ. The effect of metformin and standard therapy versus standard therapy alone in nondiabetic patients with insulin resistance and nonalcoholic steatohepatitis (NASH): a pilot trial. Therap Adv Gastroenterol 2009; 2: 157-63.

98. Chiarelli F, Di Marzio D. Peroxisome proliferator-activated receptor-gamma agonists and diabetes: current evidence and future perspectives. Vasc Health Risk Manag 2008; 4: 297-304.

99. Ratziu V, Giral P, Jacqueminet S, et al. Rosiglitazone for nonalcoholic steatohepatitis: one-year results of the randomized placebo-controlled Fatty Liver Improvement with Rosiglitazone Therapy (FLIRT) Trial. Gastroenterology 2008; 135: 100-10.

100. Ratziu V, Charlotte F, Bernhardt C, et al. Long-term efficacy of rosiglitazone in nonalcoholic steatohepatitis: results of the fatty liver improvement by rosiglitazone therapy (FLIRT 2) extension trial. Hepatology 2010; 51: 445-53.

101. Aithal GP, Thomas JA, Kaye PV, et al. Randomized, placebo-controlled trial of pioglitazone in nondiabetic subjects with nonalcoholic steatohepatitis. Gastroenterology 2008; 135: 1176-84.

102. Sanyal AJ, Chalasani N, Kowdley KV, et al. Pioglitazone, vitamin E, or placebo for nonalcoholic steatohepatitis. N Engl J Med 2010; 362: 1675-85.

103. Courrèges JP, Vilsbøll T, Zdravkovic $M$, et al. Beneficial effects of once-daily liraglutide, a human glucagon-like peptide-1 analogue, on cardiovascular risk biomarkers in patients with type 2 diabetes. Diabet Med 2008; 25: 1129-31.

104. Armstrong MJ, Gaunt P, Aithal GP, et al. Liraglutide safety and efficacy in patients with non-alcoholic steatohepatitis (LEAN): a multicentre, double-blind, randomised, placebo-controlled phase 2 study. Lancet 2016; 387: 679-90.

105. Rizvi AA, Patti AM, Giglio RV, et al. Liraglutide improves carotid intima-media thickness in patients with type 2 diabetes and non-alcoholic fatty liver disease: an 8-month prospective pilot study. Expert Opin Biol Ther 2015; 15: 1391-7.

106. de Keyser CE, Koehler EM, Schouten JN, et al. Statin therapy is associated with a reduced risk of non-alcoholic fatty liver in overweight individuals. Dig Liver Dis 2014; 46: 720-5.

107. Kiyici M, Gulten M, Gurel S, et al. Ursodeoxycholic acid and atorvastatin in the treatment of nonalcoholic steatohepatitis. Can J Gastroenterol 2003; 17: 713-8.

108. Samy W, Hassanian MA. Paraoxonase-1 activity, malondialdehyde and glutathione peroxidase in non-alcoholic fatty liver disease and the effect of atorvastatin. Arab J Gastroenterol 2011; 12: 80-5.

109. Nakamoto K, Obata T, Hirasawa A, Ih Kim K, Ryang Kim S, Tokuyama S. A future perspective on the in volvement of $n-3$ polyunsaturated fatty acid in the development of nonalcoholic fatty liver disease/non alcoholic steatohepatitis. Yakugaku Zasshi 2016; 136: 583-9.

110. Hossain N, Kanwar P, Mohanty SR. A Comprehensive updated review of pharmaceutical and nonpharma- ceutical treatment for NAFLD. Gastroenterol Res Pract 2016; 2016: 7109270 .

111. Sonmez A, Nikolic D, Dogru T, et al. Low- and high-density lipoprotein subclasses in subjects with nonalcoholic fatty liver disease. J Clin Lipidol 2015; 9: 576-82.

112. Banach M, Aronow WS, Serban MC, Rysz J, Voroneanu L, Covic A. Lipids, blood pressure and kidney update 2015. Lipids Health Dis 2015; 14: 167.

113. Villanova N, Moscatiello S, Ramilli S, et al. Endothelial dysfunction and cardiovascular risk profile in nonalcoholic fatty liver disease. Hepatology 2005; 42: 473-80. 